\title{
A participação dos conviventes com a doença falciforme na atenção à saúde: um estudo bibliográfico
}

\author{
The participation of cohabitants with sickle cell disease \\ in health care: a bibliographic study
}

Winnie Samanú de Lima Lopes (https://orcid.org/0000-0003-2433-0103) ${ }^{1}$

Romeu Gomes (https://orcid.org/0000-0003-3100-8091) ${ }^{1}$

${ }^{1}$ Departamento de Ensino, Instituto Fernandes Figueira, Fundação Oswaldo Cruz. Av. Rui Barbosa 716, Flamengo. 20550-011 Rio de Janeiro RJ Brasil. winnie.samanu@gmail.com

\begin{abstract}
This paper aims to analyze the published scientific production about the participation of the sickle cell disease (SCD) subjects and their relatives, and the autonomy and social aspects of these individuals. A qualitative bibliographic search with the Portuguese-equivalent keywords "sickle cell disease" and "participation" was used. As a result, the following themes appeared: (1) Experience of illness, highlighting coexistence and ethnic-racial issues; (2) Participation in research and the perspective of health professionals on SCD; and (3) Autonomy of cohabitants and decision-making. We can conclude that the promotion of the participation of these patients in the studies, either instrumentally, or to contextualize the results better, or - still - to enrich the authors' conclusions, can intentionally or unintentionally contribute to the greater visibility of the problem that involves being a SCD cohabitant for the subjects and their relatives. The duty to analyze intersectionally the entire context of the patient and his family context is also highlighted. Key words Sickle cell disease, Participation, Literature review, Qualitative research
\end{abstract}

Resumo $O$ artigo tem por objetivo analisar a produção científica publicada acerca da participação dos sujeitos da doença falciforme $(D F) e$ seus familiares, bem como sobre a autonomia e os aspectos sociais relacionados a esses sujeitos. Metodologicamente, utilizou-se pesquisa bibliográfica de cunho qualitativo com os descritores "doença falciforme" e "participação". Como resultados, afiguraram-se os seguintes temas: (1) Experiência do adoecimento, destacando a convivência e as questões étnico-raciais; (2) Participação em pesquisas e o olhar dos profissionais de saúde sobre a DF; e (3) Autonomia dos conviventes e tomada de decisão. Conclui-se que a promoção da participação desses portadores nos estudos, seja de uma forma instrumental, seja para melhor contextualizar os resultados, seja - ainda - para enriquecer as conclusões dos autores, pode - intencionalmente ou não - contribuir para a maior visibilidade do problema que envolve ser portador da DF para os sujeitos e seus familiares. Destaca-se também o dever de se analisar interseccionalmente todo o contexto do paciente e seu contexto familiar.

Palavras-chave Doença falciforme, Participação, Revisão bibliográfica, Pesquisa qualitativa 


\section{Introdução}

Doença falciforme (DF) designa um grupo de hemoglobinopatias caracterizadas por alterações estruturais das células sanguíneas que produzem uma hemoglobina anômala $\mathrm{HbS}$, sendo o ' $\mathrm{S}$ ' derivado do inglês sickle (foice, português) devido ao formato das células hemolíticas dos pacientes da doençá ${ }^{1,2}$.

$\mathrm{Na}$ literatura acadêmica as terminologias que designam a doença são bastante variadas. Podem ser encontrados termos como "anemia falciforme", "síndrome falcêmica", "drepanocitose" e ainda "doença das células falciformes". Segundo Silva ${ }^{3}$, o termo doença falciforme vem sendo admitido por expressar além da anemia falciforme (condição com sintomatologia presente), outras desordens causadas pela mesma mutação.

A DF é definida como uma doença genética recessiva. Os pacientes com a anemia falciforme possuem uma herança da $\mathrm{HbS}$ advinda dos pais, considerados heterozigotos simples, ou seja, portadores do traço falcêmico (sem sintomatologia expressa) $)^{4}$.

De acordo com a Organização Mundial da Saúde, cerca de $5 \%$ da população mundial é afetada por doenças hematológicas, como a DF, sendo que no Brasil estima-se cerca de 2.000.000 pessoas com o gene $\mathrm{HbS}$, como o traço falcêmico, e 8.000 com a homozigose da doença e suas variadas implicações clínicas ${ }^{5,6}$.

No Brasil, o diagnóstico para DF pode ocorrer a partir do Programa Nacional de Triagem Neonatal (conhecido como "Teste do pezinho") que, ainda que não esteja amplamente implantado, pode ser crucial para tratamento e encaminhamento para equipes de atendimento especializa$\mathrm{do}^{7}$. Já os diagnósticos tardios são realizados diante alguns agravos, causando grandes prejuízos aos pacientes, por conta da complexidade de sintomas e podendo a DF ser confundida com outras doenças como epilepsia e artrite reumatoide ${ }^{8}$.

Muito além das implicações clínicas e crises dolorosas ${ }^{9}$, a DF acarreta contundentes conflitos e impactos sociais para pacientes e seus familiares, inserindo-se na categoria de adoecimento crônico e demandando diagnóstico específico, anuência ao tratamento, medidas de autocuidado e novo estilo de vida ${ }^{10}$.

A repercussão do adoecimento crônico, principalmente em casos que afetam diretamente crianças, gera sentimento de insegurança, medo da perda e frustrações em todos que rodeiam o paciente ${ }^{11}$. Quando há uma cooperação no ambiente familiar, ansiedade, agressividade, depressão e limitações sociais podem ser superadas ${ }^{12}$.
Pela alta incidência da DF na população negra, pode haver intensas discriminações em uma sociedade fortemente racista e um sistema de saúde marcado por racismo institucional ${ }^{13}$. Sil$\mathrm{va}^{14}$ discute os embates raciais com suas problemáticas sobre a racialização e estigmatização dos pacientes com a DF como pertencente aos corpos negros no contexto norte americano, que tanto implicou em discriminações raciais, como serviu de bandeira para reivindicar do estado medidas que favorecessem negros.

Se utilizarmos a perspectiva de Goffman ${ }^{15}$, os sujeitos da DF (por conviverem o adoecimento crônico) podem ser estigmatizados e colocados em um "não-lugar" pelos socialmente considerados "normais", determinando uma invisibilidade e uma marginalização dos pacientes com a DF, eximindo assim uma postura protagonista nas decisões terapêuticas.

Goffman $^{15}$ utiliza o estigma de forma mais ampla do sentido original cunhado pelos gregos, que se vinculava a marcas corporais. Segundo ele, essa expressão se refere a um atributo depreciativo, mas sem considerar uma relação de atributos em si, mas sim de uma relação de linguagem. Nesse sentido, além de alguns casos não existirem traumas físicos visíveis, as pessoas com a DF são colocadas em posição de estigmatizadas enquanto desviantes de uma norma social. Ressalta-se a relatividade do conceito de Goffman ${ }^{15}$ onde, o que pode ser considerado estigma para uns, pode se encaixar em um padrão de normalidade para outros, sendo que "o normal e o estigmatizado não são indivíduos propriamente ditos, e, sim, perspectivas, pontos de vista, interpretações, interações" ${ }^{\prime 16}(\mathrm{p} .51)$.

A posição de estigmatizados aos conviventes com a DF pode ser expressão da falta de informação em seus meios de convívio. Dentre os profissionais de saúde, por exemplo, a opiofobia - receio pelo uso de opióides e pelo seu potencial viciante - pode acarretar dificuldades na relação e no acesso aos serviços de saúde pelos pacientes conviventes da $\mathrm{DF}^{17}$.

Faz-se fortemente necessário comentar a interseccionalidade destas posições: raça, classe social e condição crônica. Segundo Crenshaw ${ }^{18}$, o conceito de interseccionalidade vem para união de opressões sem que hierarquias sejam estabelecidas, garantindo a indissociabilidade das posições e a necessidade de luta em prol de todos os direitos inerentes às condições impostas.

Segundo Alves ${ }^{19}$, tem-se a teoria de Talcott Parsons, onde o adoecimento também era visto como um desvio e era viável a predição de um comportamento para o enfermo, com direitos e 
deveres, tanto para os pacientes quanto para condutas médicas diante da enfermidade. Ainda há resquícios dessa teoria na atualidade, principalmente, quando se observa uma a forte autoridade médica na tomada de decisões sem considerar a autonomia dos pacientes no seu processo de tratamento.

Essa postura dentro do campo dos profissionais de saúde desconsidera em nível alarmante toda situação biográfica e estoque de conhecimento dos pacientes. À luz de Schutz ${ }^{20}$, estes conceitos se relacionam a um catálogo de experiências vividas pelos pacientes que são capazes de inferir interpretações e ações voltadas a determinado aspecto de suas vidas.

As fortes implicações sociais voltadas para a compreensão dos fenômenos culturais e societários ligados à DF fazem com que seja necessária a ampliação dessa discussão. Nesse sentido, faz-se necessário incidir o foco na participação na atenção à DF dos sujeitos dessa doença e seus familiares (associados ou não em grupo) para que se possam ser pensadas ou ressignificadas ações de cuidado e integração dos pacientes nos processos de tomadas de decisão.

O conceito de participação aqui abordado, refere-se não só à participação dos conviventes em conselhos consultivos em prol da garantia de direitos, tal como preconiza os princípios do SUS, mas principalmente à participação dos pacientes que, em um processo de tomada de consciência e superação dos estigmas impostos, se tornam protagonistas de seus direitos e agente ativos em seus tratamento.

A partir dessa perspectiva, neste trabalho, objetiva-se analisar a produção científica publicada acerca da participação dos sujeitos da DF e seus familiares no tratamento, bem como sobre a autonomia e os aspectos sociais relacionados a esses sujeitos.

\section{Metodologia}

Este estudo consiste numa pesquisa bibliográfica, aqui entendida de forma genérica como aquela que utiliza fontes secundárias publicadas, no sentido de analisar as contribuições de diversos autores acerca de um assunto ${ }^{21}$. A fonte aqui privilegiada é o artigo científico por possibilitar um maior acesso em comparação com outros tipos de fontes bibliográficas.

Utilizou-se a Biblioteca Virtual em Saúde (BVS - http://brasil.bvs.br/) por ser um metabuscador capaz de sistematizar dados procedentes de outras bases como a SciELO, PubMed e Lilacs, bases relevantes para a o conhecimento científico no Brasil e em outros países. Destaca-se a grande visibilidade e confiabilidade deste metabuscador acadêmico que parte de uma iniciativa do Ministério da Saúde do Brasil, da Organização Mundial da Saúde e ainda da Organização Pan-Americana da Saúde.

A terminologia utilizada na literatura acadêmica referente aos pacientes com a doença falciforme é bastante diversa e, em sua maioria, não abarca seu contexto familiar e representa apenas os indivíduos acometidos diretamente por esta enfermidade. Para esta revisão, propõe-se o termo "conviventes com a DF" por entender que a doença aqui abordada compreende muito mais que um único indivíduo, mas sim todo seu meio de convivência em suas redes de apoio com grande intensidade.

Seguindo um modelo do movimento das pessoas com deficiência e o discurso das pessoas vivendo com HIV/AIDS, o termo "portador” não foi utilizado neste artigo por ser o verbo "portar" algo passível de remoção, não sendo contextualizado à $\mathrm{DF}^{22}$. Além deste fato, o termo "portadores" remete a lógica geneticista, o que reforça a herança genética imposta pela DF, refletindo não somente a doença sintomatológica, mas também o traço falciforme, esquivando-se de qualquer questionamento sobre responsabilização e/ou culpabilidade do discurso genético.

Outros termos foram utilizados, mas devem ser problematizados. O termo paciente foi utilizado nesta revisão de maneira abrangente e sem que a lógica biomédica e clínica seja reforçada, por ser esta uma pesquisa de cunho socioantropológico. “Sujeitos da DF” foi utilizado enquanto sinônimo de "conviventes com a DF" por acreditar que pessoas engajadas à temática não precisam necessariamente ser afetadas diretamente pela doença.

Os descritores de assuntos utilizados para esta análise foram seguramente alinhados ao núcleo central do objetivo deste artigo (DF e participação). Ressalta-se que o termo "associação de pacientes”, pensando na representação dos movimentos de pacientes e mobilização em prol da DF, relacionado ao tema aqui proposto, foi excluído como descritor por vincular como resultados apenas a associação de sintomas, medicamentos ou tratamentos referentes a doença falciforme.

O vocábulo "participação" foi determinado por definir, segundo os descritores de assuntos da BVS, participação pública ou ação comunitária. Como sinônimos do termo, a base de dados 
aponta como "Participação Comunitária", "Participação Popular", "Mobilização" entre outros. Já o termo "Doença Falciforme" aparece como equivalente a "Anemia Falciforme", "Anemia de Células Falciformes", "Doença das Células Falciformes" entre outros.

A busca realizada em 29 de dezembro de 2017, sob os termos "doença falciforme" e "participação", resultou em 34 referências. Os critérios de inclusão nesta revisão foram: (1) a caracterização como artigo científico (sendo excluídas teses e editoriais); (2) ano de publicação entre 2000 e 2017, e principalmente (3) ser definido como pesquisa qualitativa, excluindo assim trabalhos clínicos, epidemiológicos e os de cunho quantitativo em geral. Após a cumprimento dos critérios de inclusão, restaram 20 artigos.

Uma nova busca foi efetuada em 01 de março de 2018, para verificar se, na base de dados, houve a inclusão de novos artigos com o perfil desta revisão, o que não foi observado. Para uma melhor análise e para restrição da amostra, os artigos anteriores ao ano de 2000 foram excluídos desta pesquisa. Esta restrição temporal se fez pela escassez de produção disponibilizadas em plataformas online. Na pesquisa, foi identificado apenas um artigo anterior a 2000, do ano de 1973 que aborda leis e políticas a partir de tecnologias genéticas daquela época, o que não contribui significativamente com a temática aqui proposta.

Em termos de análise do acervo encontrado, de cunho qualitativo, optou-se pela técnica de análise temática adaptada por Gomes ${ }^{23}$, com base nos princípios de $\operatorname{Bardin}^{25}$. O conceito central dessa análise é o tema que "comporta um feixe de relações e pode ser graficamente apresentado através de uma palavra, uma frase um resumo" $\left(\right.$ p. 86 ${ }^{23}$. Como base nesse autor, foi percorrida a seguinte trajetória analítica: (a) identificação das ideias centrais dos trechos transcritos de todos os artigos; (b) classificação dos sentidos subjacentes às ideias em temas que resumem a produção do conhecimento acerca do assunto estudado; e (c) elaboração de sínteses interpretativas de cada tema, estabelecendo diálogo com os temas identificados na análise dos artigos com outras obras - apontadas na introdução deste trabalho - para que a discussão acerca do assunto fosse ampliada.

\section{Resultados e discussão}

Com os resultados da busca realizada, o Quadro 1 apresenta a relação de artigos analisados, seguidos de ano de publicação, país de origem e temas de destaque. Sobre o país de origem, observa-se a baixa frequência de estudos no hemisfério sul. Esta constatação pode ser explicada não necessariamente pela baixa produção destes países, mas talvez porque essa produção nem sempre atenda aos critérios de indexação da BVS. Destacam-se dois estudos ${ }^{23,24}$ do Quênia por abordar um cenário não-eurocêntrico ou americanizado na abordagem de temas referentes à informação genética.

Importante caracterizar que em sua maioria, os artigos aqui analisados tiveram como público-alvo os conviventes com a doença falciforme, direcionando olhares a entrevistas e consultas sobre a participação popular, opções terapêuticas, entre outros temas levantados neste trabalho. Apenas três artigos ${ }^{25-27}$ utilizaram como objeto de pesquisa os profissionais de saúde envolvidos na temática da DF.

Ressalta-se aqui o fato de alguns artigos abordarem mais de um tema incluído neste trabalho e ainda que a variação entre os anos se fez bastante homogênea, sendo apenas o ano de 2010 com o total de cinco publicações sob descritores analisados.

Emergiram da análise dos conteúdos dos artigos os seguintes temas: (1) Experiência do adoecimento, relacionado à convivência com a DF e as questões étnico-raciais; (2) Participação em pesquisa e o olhar dos profissionais de saúde sobre a DF e (3) Autonomia dos conviventes e tomada de decisão. Esses temas - que não são necessariamente excludentes - relacionam-se direta ou indiretamente à participação dos conviventes com a DF.

\section{Experiência do adoecimento}

Este tema caracteriza-se pela a experiência e a perspectiva do paciente diante o adoecimento pela DF.

Silva et al. ${ }^{28}$ abordam o papel crucial da família (como "unidade produtora de cuidado" no enfrentamento da cronicidade) e as redes de apoio que suportam a família envolvida na pesquisa. Com a representação em um ecomapa, as instituições formais e informais de cuidado e sua contribuição na manutenção do cotidiano dos conviventes, como família estendida (avós, tios etc), associações de pacientes e suporte religioso são apontadas na pesquisa. Esses autores ressaltam o papel das associações de pacientes como um espaço de compartilhamento de experiências e de fortalecimento de vínculos e afetividade entre os pares. 
Quadro 1. Caracterização dos artigos analisados.

\begin{tabular}{|c|c|c|c|}
\hline Estudo & Ano & País/Origem & Tema \\
\hline Noke et al. ${ }^{25}$ & 2016 & Reino Unido & Profissionais de saúde \\
\hline Patterson et al. ${ }^{41}$ & 2015 & Estados Unidos & Participação em pesquisa \\
\hline Marsh et al. ${ }^{23}$ & 2013 & Reino Unido & Profissionais de saúde \\
\hline Silva et al. ${ }^{28}$ & 2013 & Brasil & Experiência do adoecimento \\
\hline Lebensburger et al. ${ }^{42}$ & 2013 & Estados Unidos & Participação em pesquisa \\
\hline Jones e Broome ${ }^{50}$ & 2001 & Estados Unidos & $\begin{array}{l}\text { Participação em pesquisa/Autonomia dos } \\
\text { conviventes e tomada de decisão }\end{array}$ \\
\hline Daulton $^{29}$ & 2010 & Estados Unidos & Experiência do adoecimento \\
\hline Reed $^{39}$ & 2011 & Reino Unido & Experiência do adoecimento \\
\hline Marsh et al. ${ }^{24}$ & 2013 & Quênia / Estados Unidos & Profissionais de saúde \\
\hline Fry $^{38}$ & 2005 & Brasil & Experiência do adoecimento \\
\hline Tsianakas et al. ${ }^{26}$ & 2010 & Reino Unido & Profissionais de saúde \\
\hline Benjamin $^{43}$ & 2011 & Estados Unidos & Participação em pesquisa \\
\hline Liem et al. ${ }^{44}$ & 2010 & Estados Unidos & Participação em pesquisa \\
\hline Lattimer $^{40}$ & 2010 & Estados Unidos & $\begin{array}{l}\text { Experiência do adoecimento/Autonomia dos } \\
\text { conviventes e tomada de decisão }\end{array}$ \\
\hline Bakshi et al. ${ }^{27}$ & 2017 & Estados Unidos & Profissionais de saúde \\
\hline Hankins $^{45}$ & 2010 & Estados Unidos & Participação em pesquisa \\
\hline Hassel et al. ${ }^{46}$ & 2008 & Estados Unidos & $\begin{array}{l}\text { Participação em pesquisa/Autonomia dos } \\
\text { conviventes e tomada de decisão }\end{array}$ \\
\hline Willen et al. ${ }^{30}$ & 2014 & Estados Unidos & Experiência do adoecimento \\
\hline Hankins et al. ${ }^{48}$ & 2007 & Estados Unidos & Autonomia dos conviventes e tomada de decisão \\
\hline Knopf et al. ${ }^{49}$ & 2008 & Estados Unidos & Autonomia dos conviventes e tomada de decisão \\
\hline
\end{tabular}

Doulton $^{29}$ descreve o programa de transição de pacientes com a DF da infância para a fase adulta, apontando os grandes avanços na medicina, a expectativa de vida dos pacientes com a DF aumentou significativamente, de 14 para 50 $\operatorname{anos}^{29}$. Desta forma, torna-se necessário a adaptação dos serviços e atendimentos para esta nova realidade. $\mathrm{O}$ autor propõe a educação em saúde centrada no autocuidado e ressalta a necessidade de uma análise das experiências dos conviventes, não os reduzindo a doença, mas observando aspectos culturais, socioeconômicos e todo o contexto familiar. Consideram ainda as tentativas dos sujeitos de adequação e enquadramento na funcionalidade imposta socialmente.

Willien et al..$^{30}$ apresentam uma revisão voltada aos pacientes da DF, tratando incertezas e possíveis complicações experienciadas pelo adoecimento e suas potenciais complicações como possibilidades de infecções, crises sob mudança de altitude e rotina de vacinações. Os autores, assim como Douton $^{29}$, ressalta a necessidade de criar medidas que acompanhem o aumento da expectativa de vida dos pacientes com DF em prol da melhoria da qualidade de vida.
A estreita relação com o adoecimento crônico e a experiência com a DF pode ser entendida a partir de algumas ideias de Schutz ${ }^{31}$. Para esse autor $^{31}$, cada indivíduo constrói o seu próprio mundo. Entretanto, essa construção não surge a partir do nada. O indivíduo constrói com base nas relações que estabelece com outros indivíduos. $\mathrm{O}$ mundo da vida é o mundo intersubjetivo que antecede a vida cada um e toda interpretação acerca desse mundo baseia-se num estoque de experiências prévias ${ }^{20}$. Esse processo intersubjetivo pode produzir um grande estoque de conhecimento que se torna a base para movimentos associativos de autoajuda ou de apoio à pacientes ${ }^{32}$.

Destaca-se aqui a pesquisa de Silva et al. ${ }^{28}$ que enfatiza o papel da família como "unidade produtora de cuidado". Esse ideal se faz fortemente necessário ao se analisar o grande envolvimento e também o estoque de conhecimento adquirido não só dos pacientes, mas também de suas famílias, geralmente representados pela figura materna enquanto cuidadoras diretas, que além de se inteirarem clinicamente da temática, propondo medidas de autocuidado, se engajam na luta pela garantia de direitos pelos movimentos associativos. 
Barbosa $^{33}$ e Motter e Okabayashi ${ }^{34}$ definem os movimentos associativos de pacientes como redes formadas geralmente por pacientes, familiares e/ou profissionais de saúde que investem na remediação das faltas do sistema de saúde oficial. As associações de pacientes com a doença falciforme possuem um importante papel na construção de uma autoestima e um protagonismo diante o adoecimento, bem como um espaço de compartilhamento de informações, experiências e de cooperação ${ }^{35}$.

Com base na teoria do estigma de Goffman, Moreira e Souza ${ }^{36}$ observam que o associativismo integra pessoas em torno de uma causa que envolve um estigma. Traduz-se pela relação entre os "iguais" (pessoas que compartilham o estigma) e os "informados" (pessoas que se solidarizam com as causas dos estigmatizados). Tais associações, que são ancoradas no conhecimento laico da convivência e nas reivindicações por um reconhecimento social ampliado, podem recrutar outros "informados", "como os profissionais de saúde que, por serem portadores de conhecimento técnico, produzem um mix no processo de solidariedade/alteridade/identificação/reconhecimento" ${ }^{36}$ (p.57).

Uma dimensão a ser considerada na experiência com a DF é a raça. A ligação entre raça e a doença falciforme foi motivada pela origem da doença que, apesar de se ter admitido uma origem multirregional, a hemoglobina HbS sempre foi vinculada aos corpos negros ${ }^{37}$, configurando assim, um grande dilema na temática da doença falciforme, principalmente no Brasil e nos Estados Unidos, tornando ainda mais complexo este processo de adoecimento e suas experiências.

Peter Fry ${ }^{38}$ levanta o forte significado racial da DF e o persistente papel do movimento negro na consolidação de políticas públicas voltadas aos enfermos da DF e seus familiares. Afirma que, a invisibilidade da população negra e sua falta de responsabilização de seus corpos que foi ressignificada no contexto da DF, em que campanhas promoviam e incumbiam aos negros a profilaxia contra a DF nos EUA, na década 1970. Com este direcionamento de responsabilidades, criou-se uma comunidade negra mais real e participativa na sociedade. $\mathrm{O}$ autor destaca também o forte papel feminino no movimento negro em prol da garantia de direitos pela DF.

Outro artigo encontrado nesta busca bibliográfica com abordagem racial e de gênero é Reed $^{39}$, que traz a descrição da influência da etnia e do gênero no processo de participação de homens na triagem pré-natal da doença falciforme e talassemias. Segundo a autora, apesar de todos os estereótipos de pais negros ausentes, os integrantes de minorias negras se mostraram mais abertos a visão equitativa de gênero e grandes apoiadores durante a gestação de suas parceiras em relação aos homens brancos britânicos.

Lattimer $^{40}$ aborda as dificuldades de atendimento hospitalar em crises vaso-oclusivas em pacientes com a doença falciforme, como atraso no tratamento medicamentoso, exagero na expressão da dor e opiofobia e, a partir de questionário, busca quantificar a experiência dos conviventes da DF, supondo uma grande discrepância entre os demais pacientes em atendimento hospitalar.

A pesquisa de Lattimer $^{40}$, apesar de descrever um trabalho quantitativo de coorte, foi incluída nesta revisão por apresentar uma tentativa de mensurar uma experiência. E sua conclusão foi que, de fato, os pacientes com a doença falciforme enfrentam mais problemas durante as internações hospitalares do que os demais pacientes. Os autores sugerem ainda que as disparidades no atendimento se devem ao caráter étnico racial dos envolvidos, que recebem menos atenção não verbal, empatia e informação durante sua estada hospitalar.

A DF enquanto doença racializada atinge em sua maioria corpos negros, que são vistos e tratados como desviantes diante a autoridade médica branca detentora dos conhecimentos formais de cura. Abordar as relações étnico-raciais em saúde para o caso da doença falciforme se faz de grande relevância, principalmente ao referir Lattimer ${ }^{40}$ artigo encontrado nesta revisão - a grande disparidade no atendimento entre pacientes negros com a doença falciforme nos serviços de saúde em relação aos demais pacientes. Porém destaca-se aqui a necessidade de uma abordagem interseccional no enfrentamento da discriminação e do adoecimento crônico, que releve todos os critérios de raça, gênero e classe que se apresentam tão coesos na sociedade brasileira e que evidenciam às mulheres negras e conviventes com a doença falciforme em uma condição extrema e singular.

Com base em Crenshaw ${ }^{18}$, faz-se fortemente recomendada a análise interseccional dos conviventes com a doença falciforme, principalmente ao se considerar a confluência das categorias raça, classe social e a cronicidade da doença, enquanto sistemas múltiplos de subordinação, na constituição das subjetividades dos pacientes e sua rede de apoio. A luta pela equidade dentro desta roda de opressões reflete na conquista por autonomia e participação para os conviventes com a DF em 
todos os espaços de decisão onde ainda possuem uma postura periférica.

\section{Participação em pesquisas clínicas}

Neste tema, destacam-se artigos que tratam da participação dos pacientes com a doença falciforme em pesquisa clínicas para criação de novos protocolos e na melhoria dos tratamentos direcionados à doença.

Patterson et al. ${ }^{41}$ tiveram por objetivo identificar os benefícios e as barreiras no recrutamento e participação de pacientes com a DF em pesquisas clínicas pediátricas. Com objetivo similar, Lebensburger et al. ${ }^{42}$ levantam os empecilhos e facilitadores na inserção em pesquisas clínicas voltadas ao tratamento com Hydroxyurea, ainda com grandes questionamentos pela comunidade com DF. Jones e Broome ${ }^{24}$ também seguiram uma abordagem sobre participação em pesquisas clínicas, que a partir da realização de grupos focais voltados a adolescentes afro-americanos, foi possível questionar esses pacientes em prol de estratégias para o recrutamento e participação em pesquisas.

Benjamin $^{43}$, a partir de uma etnografia, traz a análise das respostas dos familiares quanto ao recrutamento para transplante de células-tronco, levantando as incertezas e desconfianças quanto a este tratamento.

Liem et al. ${ }^{44}$ entrevistaram pais e responsáveis por crianças com a DF sobre consentimento na participação em pesquisas clínicas e os critérios utilizados para a tomada de decisão. Hankins ${ }^{45}$ traz uma análise de Liem et al. ${ }^{44}$, apontando para a complexidade em recrutar pacientes com DF, inseridos em um contexto minoritário e muitas vezes em situação de vulnerabilidade, e ainda destaca o papel crucial de profissionais sensíveis ao contexto socioeconômico e ao cenário familiar.

Já Hassell et al. ${ }^{46}$ apresentam propostas elaboradas pela Sociedade Americana de Hematologia Pediátrica na Cúpula de DF em prol da unificação de um discurso em pesquisas clínicas e de ação. Dentre as prerrogativas apontadas têm-se a otimização do acesso aos cuidados em saúde, a ampliação das abordagens em pesquisas básicas e ainda a melhoria no papel de advocacy, serviços e captação de recursos.

A participação em pesquisas clínicas pode oferecer aos pacientes da DF, ainda que em fase de teste e desenvolvimento, acesso a novas tecnologias, medicamentos e procedimentos de alta especificidade. Apesar dos fortes critérios éticos e das grandes vantagens na inclusão em pesquisas deste tipo, a recusa dos conviventes pode nascer pelo receio aos efeitos colaterais desconhecidos, ou ainda pela objetificação dos corpos como foco da pesquisa.

Outro forte empecilho para a integração desses pacientes às pesquisas clínicas pode surgir pelas disparidades culturais e dificuldade de comunicação entre os pesquisadores e o público alvo. No meio acadêmico e médico, sobrepõe-se e valoriza-se um linguajar rebuscado com a utilização de termos técnicos e específicos voltados às doenças e suas implicações, porém, muitas vezes os profissionais engajados em pesquisas não conseguem traduzir de maneira esclarecedoras seus objetivos aos potenciais participantes da pesquisa, gerando conflito e a recusa da participação ${ }^{47}$.

Os estudos aqui analisados não deixaram transparecer a forma e contexto em que a participação foi requisitada, o que pode ser considerada de extrema relevância para a resposta positiva ou negativa dos conviventes. Quando o contato se faz em um ambiente hospitalar, a autoridade que solicita se torna muito mais impositiva, por ser um ambiente controlado pela autoridade médica, colocando em questão até a qualidade do atendimento em decorrência de determinadas respostas.

A escolha da participação ou não em pesquisas clínicas interfere diretamente sobre a autonomia dos conviventes e em sua postura protagonista diante o processo de adoecimento e suas possibilidades de tratamentos terapêuticos. Assumir o protagonismo frente ao cuidado e as escolhas de tratamento podem quebrar o forte ciclo da discriminação e estigmas em torno da doença, bem como construir uma autoestima para o enfrentamento do adoecimento crônico.

Para que sejam ampliada a discussão acerca da participação dos pacientes em pesquisas clínicas, destacam-se artigos encontrados ${ }^{23-27}$, que apresentam os olhares dos profissionais de saúde diante a doença falciforme e seus processos que podem influenciar tanto os limites acerca da mencionada participação, como na relação médico-paciente.

Noke et al. ${ }^{25}$ exploram como os profissionais de saúde do Reino Unido decidem testar crianças para a identificação do traço falciforme. Segundo o artigo, as diretrizes internacionais não incentivam o teste por possíveis danos psicológicos e ainda por não apresentar riscos reprodutivos imediatos. Os autores destacam a realidade do Reino Unido diante dos debates necessários em prol da DF e pela autonomia dos pacientes e suas tomadas de decisão. Concluem que há uma 
falta de padronização, treinamento e ciência das diretrizes internacionais por parte dos profissionais de saúde, sugerindo assim maior orientação destas equipes, principalmente em prol do reconhecimento dos direitos das crianças e sua autonomia dos conviventes.

Marsh et al. ${ }^{23}$ entrevistaram 62 moradores de Kilifi, no Quênia, para consultar o posicionamento da população sobre a postura de pesquisadores e profissionais da saúde frente a casos de paternidade desalinhada, envolvendo a doença falciforme. Por se tratar de uma doença genética, a expressão da DF se dá pela herança de um gene da mãe e outro do pai. Desta forma o artigo problematiza as figuras paternas que não condizem com a constituição genética para a DF. Várias foram as questões levantadas pelos entrevistados como: Exposição da figura materna, agravamento da doença na criança, separação/divórcio, possibilidade de violência contra a mulher, entre outros. Os autores concluem que, embora as perguntas não tenham sido clarificadas, vários apontamentos éticos foram elucidados ao longo da pesquisa, bem como a necessidade de consulta da comunidade e de todas as partes envolvidas no processo de tomada de decisão.

Um segundo artigo da equipe de Marsh $^{24}$ aborda como os pesquisadores devem tratar as informações e dados sobre a doença falciforme descobertos em pesquisas. A divulgação dos dados sobre a DF foi fortemente apoiada pelos entrevistados, quando devidamente esclarecidos os benefícios sociais deste ato.

Tsianakas et al..$^{26}$ tratam da oferta e aceitabilidade de um programa de triagem pré-natal no Reino Unido para detecção da doença falciforme e talassemias, bem como as barreiras e os facilitadores dessa oferta. Os autores observam a falta de informação sobre a DF e as talassemias pelas grávidas, o que fez com que os médicos designassem o teste como rotina, esquivando as mulheres de qualquer possibilidade de decisão quanto à triagem. Outro empecilho descrito na pesquisa refere-se à ausência de intérpretes durante as consultas por se tratar de pacientes de primeira língua não-inglesa. Quanto aos facilitadores, foram citadas as atitudes positivas dos médicos frente ao programa de triagem, bem como o desejo das gestantes por crianças saudáveis.

Bakshi et al. ${ }^{27}$ apresentam a perspectiva médica diante a escolha dos pacientes pelos tratamentos para a doença falciforme. Segundo os autores, os médicos especialistas em doença falciforme, poderiam assumir duas abordagens: a colaborativa, que visa a discussão e apresentação de todas as possibilidades de tratamento, e a proponente, que se ancora a um tratamento e na tentativa de convencimento do paciente em favor de determinada terapia. Essas abordagens ainda são permeadas por fatores como: gravidade da doença, características do enfermo e abordagens institucionais. Além disso, os autores ressaltam a necessidade e o envolvimento dos conviventes no processo de escolha, proporcionando uma decisão compartilhada quanto ao tratamento do paciente com DF.

Como proposta para uma conformidade entre os profissionais de saúde e os conviventes com a DF, supõe-se a qualificação destas equipes de saúde, em busca de maior compreensão da temática que deve ir além dos aspectos físicos e clíni$\cos$, mas que abarquem uma visão mais humana e integral dos pacientes e seus familiares. Esta integração é fundamental para a relação entre os conviventes e suas redes de cuidado e apoio, o que contribui ainda mais para a construção de uma postura positiva frente à $\mathrm{DF}$, bem como o envolvimento dos conviventes nos processos de escolhas de tratamento.

Pelas lentes de Goffman ${ }^{15}$, o estigma e a marginalização dos "não-lugares" impostos aos conviventes com a DF apresentam-se nos artigos analisados de forma bastante subjetiva. Destaca-se a ênfase dada à necessidade do envolvimento dos pacientes tanto em pesquisas clínicas, como no processo de tomada de decisão como um reflexo da postura marginalizada assumida e incutida aos pacientes de seu não-lugar enquanto pessoa estigmatizada socialmente. Nesse sentido, a participação dos conviventes com a DF pode tirar ou minimizar o seu "não-lugar", deslocando-o da invisibilidade para um protagonismo.

\section{Autonomia dos conviventes e tomada de decisão}

Em geral, os artigos que se relacionam a este tema tratam do envolvimento dos pacientes no processo de tomada de decisões diante medidas terapêuticas e como estes pacientes lidam com os tratamentos apresentados. Hankins et al. ${ }^{48}-$ ao investigarem fatores que influenciam a tomada de decisão sobre tratamentos para a DF - observam que a opção dos conviventes pelo tratamento medicamentoso com Hidroxiureia em detrimento do transplante de células-tronco ou da transfusão de sangue não acarretou diferenças significativas entre a qualidade de vida dos pacientes em relação ao tratamento escolhido. Esses autores destacam a importância de crianças e adolescentes expressarem pontos de vistas em relação ao tratamento e 
de profissionais discutirem os riscos e benefícios de cada terapia com os conviventes para que a tomada de decisão compartilhada seja efetivada.

Knopf et al. $^{49}$ abordam as preferências de adolescentes com DF no processo de tomada de decisão, e quão compatível essas decisões eram com a dos pais. Esses autores consideram que o envolvimento dos conviventes nas tomadas de decisão relativas ao adoecimento crônico, podem aumentar as expectativas e melhorar a qualidade de vida dos pacientes. Concluem que, apesar dos fortes benefícios da autonomia dos conviventes, os adolescentes e pais preferiram tomada de decisão passiva, com influências de fatores como idade, educação parental e estágio de saúde geral.

Hassel et al. ${ }^{46}$, além de apontar as grandes disparidades na assistência à saúde aos pacientes com a DF, valorizam o envolvimento da comunidade como fundamental para o tratamento dessa doença. Esses autores reconhecem as vantagens da inclusão da inclusão dos conviventes no processo de decisão em torno da doença e valorizam a educação em saúde esses sujeitos.

Jones e Broome ${ }^{50}$ também destacam a autonomia dos pacientes e tomada de decisão como plano de fundo de uma discussão sobre a socialização de adolescentes em adoecimentos crônicos diversos. Para os autores, pacientes com a DF têm necessidade de ter maior controle no seu tratamento comparado aos pacientes diabéticos analisados no mesmo estudo.

Lattimer ${ }^{40}$ concluem que pacientes com mais informações e mais envolvidos no tratamento da DF expressam satisfação acerca da relação médico-paciente, têm uma melhora em seu estado de saúde e apresentam uma queda no número de internações.

A valorização do protagonismo do convivente com a DF também reflete na construção de sua subjetividade, considerando uma abordagem compreensivista e ressaltando a individualidade e as diferenças de percepções e experiências dos pacientes e dos que convivem com a doença falciforme.

O envolvimento do paciente nos processos de decisão de tratamento, pode evidenciar uma postura autônoma do convivente com a DF, e interferir na aceitação da doença, fazendo com que medidas de autocuidado e diferenças significativas sejam incorporadas à rotina do paciente, impactando fortemente no adoecimento. Para isso, é importante que estigmas sejam superados e a intersubjetividade de conviventes com DF e profissionais de saúde sejam posta em diálogo.

\section{Conclusão}

A análise aqui realizada destaca a necessidade alarmada do desenvolvimento de pesquisas voltadas para os conviventes com a doença falciforme. Os grandes avanços em terapias, principalmente em novos medicamentos, aumentaram significativamente a expectativa de vida destes pacientes, o que aumenta as incertezas e inseguranças dos pacientes quanto ao futuro pouco conhecido.

Ressalta-se a imprescindível participação dos sujeitos da DF em pesquisas, não só as de cunho clínico e quantitativo, mas também as de caráter qualitativo, para o compartilhamento de experiências e para levantar a voz dos conviventes enquanto protagonistas do processo do cuidado, e não apenas como "público-alvo" ou "objeto de pesquisa”. Para isto, sugere-se abordagens menos hierarquizada, explicitando de forma objetiva os enfoques e os benefícios da participação, bem como as futuras contribuições e seu impacto na qualidade de vida para os participantes e para as próximas gerações.

Alguns dos estudos analisados possivelmente tenham estimulado ou considerado a participação de pacientes da DF e de seus familiares com uma conotação instrumental para a viabilização das pesquisas, em termos de colaboração no recrutamento, na composição de amostras e no envolvimento investigativo. Outros talvez tenham aproveitado essa participação para melhor analisar seus achados ou contextualizar recomendações para se lidar com o cuidado da DF. Outros, ainda, com base na participação de sujeitos e familiares, enriqueceram suas conclusões, deslocando-as da simples verificação de como a doença era percebida para conseguir captar a experiência de se viver a doença e, com isso dentre outros contributos - subsidiar a atenção à saúde de pessoas com DF. Seja qualquer uma das situações, os estudos - intencionalmente ou não - contribuíram para a maior visibilidade do problema que envolve ser paciente dessa doença para os sujeitos e seus familiares.

Os temas aqui abordados, dentro do contexto de participação dos conviventes com a DF, se fazem fortemente integrados ao refletirem a construção de uma autonomia frente às decisões terapêuticas, e também na composição de suas subjetividades diante da DF.

Por fim, destaca-se a necessidade de serem desenvolvidos novos estudos socioculturais de caráter qualitativo que possam promover a ampla divulgação de seus resultados não só nos es- 
paços acadêmicos, como também para os conviventes com a DF.

\section{Colaboradores}

WSL Lopes foi responsável pela coleta e análise dos dados, redação e revisão do manuscrito. $\mathrm{R}$ Gomes foi responsável pela atuação na redação, revisão do artigo e adição de partes significativas.

\section{Referências}

1. Felix AA, Souza HM, Ribeiro SBF. Aspectos epidemiológicos e sociais da doença falciforme. Rev Bras Hematol Hemater 2010; 32(3):203-208.

2. Lobo C, Marra VN, Silva RMG. Crises dolorosas na doença falciforme. Rev Bras Hematol Hemater 2007; 29(3):247-258.

3. Silva ACR. Compartilhando genes e identidades: orientação genética, raça e políticas de saúde para pessoas com doença e traço falciforme em Pernambuco: Editora UFPE; 2014.

4. Brasil. Ministério da Saúde (MS). Secretaria de Atenção à Saúde. Departamento de Atenção Especializada. Manual de conduta básica na Doença Falciforme. Brasília: MS; 2006.

5. World Health Organization (WHO). Sickle-cell disease and other hemoglobina disorders [acessado 2016 Jun 7]. Disponível em: http://www.who.int/mediacentre/factsheets/fs308/en/

6. Cançado RD, JA Jesus. A doença falciforme no Brasil. Rev Bras Hematol Hemater 2007; 29(3):203-206.

7. Ramalho AS, Magna LA, Paiva-e-Silva RB. A Portaria nº $822 / 01$ do Ministério da Saúde e as peculiaridades das hemoglobinopatias em saúde pública no brasil. Cad Saúde Pública 2003; 19(4):1195-1199.

8. Lopes WSL. O impacto social da doença falciforme em comunidades quilombolas de Paracatu, Minas Gerais, Brasil [dissertação]. Coimbra: Universidade de Coimbra; 2013.

9. Bender MA. Sickle cell disease. Washington: University of Washington; 2017.

10. Rodrigues CCM, Araújo IEM, Melo LL. A família da criança com doença falciforme e a equipe enfermagem: revisão crítica. Rev Bras Hematol Hemoter 2010; 32(3):257-264.

11. Ataíde CA. O impacto do diagnóstico: a implicação da doença falciforme para o contexto familiar [dissertação]. Belo Horizonte: Universidade Federal de Minas Gerais; 2006.

12. Santos ARR, Miyazaki COM. Grupo de sala de espera em ambulatório de doença falciforme. Rev Bras Terapia Comportamental Cognitiva 1999; 1(1):41-48. 
13. López LC. The concept of institutional racism: applications within the healthcare field. Interface (Botucatu) 2012; 40(16):121-134.

14. Silva ACR. A racialização da saúde: (re)discutindo a relação natureza $\mathrm{x}$ cultura na construção de identidades étnicas/raciais. In: $26^{a}$ Reunião Brasileira de Antropologia 2008, Porto Seguro; Anais da 26a reunião Brasileira de antropologia; 2008.

15. Goffman E. Estigma - Notas sobre a manipulação da identidade deteriorada. 2004.

16. Piccolo GM, Mendes EG. Dialogando com Goffman: contribuições e limites sobre a Deficiência. Poíesis Pedagógica 2012; 10(1):46-63.

17. Kulkamp IC, Barbosa CG, Bianchini KC. Percepção de profissionais da saúde sobre aspectos relacionados à dor e utilização de opióides: um estudo qualitativo. Cien Saude Colet 2008; 13(Supl.):721-731.

18. Crenshaw K. Documento para o encontro de especialistas em aspectos da discriminação racial relativos ao gênero. Rev Estudos Feministas 2002; 171(1):171-188.

19. Alves PC. A experiência da enfermidade: Considerações teóricas. Cad Saúde Pública 1993; 9(3):263-271.

20. Schutz A. A fenomenologia e as relações sociais. Rio de Janeiro: Zahar;1979.

21. Sassaki R. Terminologia sobre deficiência na era da inclusão. s/a. Disponível em: https://acessibilidade. ufg.br/up/211/o/TERMINOLOGIA_SOBRE_DEFICIENCIA_NA_ERA_DA.pdf?1473203540

22. Gomes R. Análise e interpretação de dados de pesquisa qualitativa. In: Minayo MCS, organizadora. Pesquisa social: teoria, método e criatividade. Petrópolis: Vozes; 2007. p. 79-108.

23. Marsh V, Kombe F, Fitzpatrick R, Molyneux S, Parker $M$. Managing misaligned paternity findings in research including sickle cell disease screening in Kenya: 'Consulting communities' to inform policy. Soc Sci Med 2013; 96:192-199

24. Marsh V, Kombe F, Firzpatrick R, Williams TN, Parker $\mathrm{M}$, Molyneux S. Consulting communities on feeback of genetic findings in international health research: sharing sickle cell disease and carrier information in coastal Kenya. BMC Medical Ethics 2013; 14:41.

25. Noke M, Peters S, Wearden A, Ulph F. A qualitative study to explore how professionals in the United Kingdom make decisions to test children for a sickle cell carrier status. Eur J Human Genetics 2016; 24:164170.

26. Tsianakas V, Calnan M, Atkin K, Dormandy E, Marteau M. Offering antenatal sickle cell and thalassaemia screening to pregnant women in primary care: a qualitative study of GP's experiences. Br J General Practice 2010; 60(580):822-828.

27. Bakshi N, Sinha CB, Ross D, Khemani K, Loewenstein G, Krishnamurti L. Proponent or collaborative: Physician perspectives and approaches to disease modifying therapies in sickle cell disease. PLoS ONE 2017;12(7):e0178413.

28. Silva AH, Bellato R, Araújo LFS. Cotidiano da família que experiencia a condição crônica por anemia falciforme. Rev Eletr Enf 2013;15(2):437-446.

29. Doulton DM. From cradle to commencement: Transitioning pediatric sickle cell disease patients to adult providers. J Pediatr Nurs 2010; 27(2):119-123.
30. Willen SM, Thornburg CD, Lantos PM. The traveler with sickle cell disease. J Travel Med 2014; 21(5):332339.

31. Schutz A. El problema de la realidade social. Buenos Aires: Amorrurtu; 2008.

32. Frossard VC, Dias MCM. O impacto da internet na interação entre pacientes: novos cenários em saúde. Interface (Botucatu) 2016; 20(57):349-361.

33. Barbosa RL. Associações de pacientes, associações de doentes, organizações de pacientes, grupos consumidores de saúde... afinal, sobre o que se está falando?. In: Um olhar social para o paciente - Actas do I Congresso Iberoamericano de Doenças Raras. Coimbra: Centro de Estudos Sociais; 2015. p. 20-33.

34. Motter DG, Okabayashi RY. Voluntariado na perspectiva de gênero: Reflexões a partir de uma experiência com a Associação dos Voluntários do Hospital Universitário de Londrina. Serv Soc Rev 2005;7(2):1-6.

35. Andrade GRB, Vaitsman J. Apoio social e redes: conectando solidariedade e saúde. Cien Saude Colet 2002; 7(4):925-934.

36. Moreira MCN, Souza WS. A microssociologia de Erving Goffman e a análise relacional: um diálogo metodológico pela perspectiva das redes sociais na área de saúde. Teoria Soc 2002; 9:38-61.

37. Assis ES. Estudo das sindromes falcémicas em comunidade quilombola, Sergipe/Brasil [dissertação]. Aracaju: Universidade Tiradentes; 2010.

38. Fry PH. O significado da anemia falciforme no contexto da política racial do governo brasileiro 19952004. Hist Cien Saude-Manguinhos 2005; 12(2):347370.

39. Reed K. 'He's the dad isn't he?' Gender, race and the politics of prenatal screening. Ethn Health 2011; 16(45):327-341.

40. Lattimer L. Problematic hospital experiences among adult patients with sickle cell disease. $J$ Health Care Poor Underserved 2010; 21(4):1114-1123.

41. Patterson CA, Chavez V, Mondestin V, Deatrick J, Li Y, Barakat LP. Clinical trial decision making in pedriatric sickle cell disease: a qualitative study of perceived benefits and barriers to participation. J Pediatr Hematol Oncol 2015; 37(6):415-422.

42. Lebensburger JD, Sidonio RF, DeBaun MR, Safford MM, Howard TH, Scarinci IC. Exploring barriers and facilitators to clinical trial enrollment in the contexto of sickle cell anemia and hydroxyrea. Pediatr Blood Cancer 2013; 60:1333-1337.

43. Benjamin R. Organized ambivalence: when sickle cell disease and stem cell research converge, Ethnicity Health 2011; 16(4-5):447-463.

44. Liem RI, Cole AH, Pelligra AS, Mason M, Thompson AA. Parental atitudes toward research participation in pedriatric sickle cell disease. Pediatr Blood Cancer 2010; 55:129-133.

45. Hankins J. Should my child participate in this research study? Pediatr Blood Cancer 2010; 55:12-13.

46. Hassell K, Pace B, Wang W, Kulkarni R, Luban N, Johnson CS, Eckman J, Lane P, Woods WG. Sickle cell disease summit: From clinical and research disparity to action. Am J Hematol 2008; 84(1):39-45. 
47. Kauffman JC. Começar o trabalho: rapidez, flexibilidade e empatia. In: A Entrevista Compreensiva - Um Guia Para Pesquisa de Campo. Rio de Janeiro: Vozes, 2015.

48. Hankins J, Hinds P, Day S, Carroll Y, Li C, Garvie P, Wang W. Therapy preference and decision-making among patients with severe sickle cell anemia and their families. Pediatr Blood Cancer 2007; 48:705-710.

49. Knopf JM, Hornung RW, Slap GB, DeVellis RF, Britto MT. Views of treatment decision making from adolescentes with chronic illnesses and their parentes: a piloty study. Health Expectations 2008;11:343-354.

50. Jones FC, Broome ME. Focus groups with african american adolescentes: Enhancing recruitment and retention in intervention studies. J Pediatr Nurs 2001; 16(2):88-95.

51. Bardin L. Análise de Conteúdo. Lisboa: Edições 70; 1979.

Artigo apresentado em 14/08/2018

Aprovado em 21/11/2018

Versão final apresentada em 23/11/2018 